\title{
Cytoreductive Surgery and HIPEC in the Baltic States: An International Scientific Workshop with Live Surgery
}

\author{
Eligijus Poskus ${ }^{a}$ Kestutis Strupas ${ }^{b}$ Vadim Gushchin ${ }^{c}$ Paul H. Sugarbaker ${ }^{d}$ \\ ${ }^{a}$ Center of Abdominal Surgery, Vilnius University Hospital, Vilnius, Lithuania, \\ ${ }^{b}$ Clinic of Gastroenterology, Nephrourology and Surgery, Center of Abdominal Surgery, Faculty of Medicine, Vilnius University, \\ Santariskiu Clinics, Vilnius, Lithuania, \\ ${ }^{\mathrm{c}}$ Center for Cancer Care, Mercy Hospital, Baltimore, MD, USA, \\ ${ }^{\mathrm{d} C e n t e r}$ for Gastrointestinal Malignancies, MedStar Washington Hospital Center, Washington, DC, USA
}

\section{Keywords}

Hyperthermic intraperitoneal chemotherapy - HIPEC .

Cytoreductive surgery - CRS . Pseudomyxoma peritonei .

Ovarian cancer - Colorectal cancer . Peritoneal metastases .

Peritonectomy

\section{Summary}

Background: Around the globe a new interest in the multidisciplinary management of peritoneal metastases using neoadjuvant chemotherapy, cytoreductive surgery (CRS), hyperthermic intraperitoneal chemotherapy (HIPEC), and adjuvant systemic chemotherapy has occurred. The combined use of these treatment modalities has required the creation of centers of excellence to manage patients with peritoneal metastases with a high level of success as well as a low incidence of adverse events. Methods: A 2-day workshop hosted by the Center of Abdominal Surgery, Vilnius University Hospital, with 230 participants was organized to explore the current practice in the Baltic states. Live surgery with video transmission initiated the efforts. Then, presentations by five experts from high-volume peritoneal surface malignancy centers were made and discussed. A summary of the efforts to date in Lithuania and Estonia was presented and collected for publication. Results: The live surgery served as a focal point for all subsequent presentations. The five invited speakers reviewed the rationale, current literature, indications and contraindications, implementation, and current European guidelines for management. The results of CRS and HIPEC from five centers in Lithuania and Estonia currently active revealed 127 patients treated to date, half of whom carried a diagnosis of ovarian cancer. There was an incidence of major complications of $11.8 \%$ and a mortality of $1.6 \%$. Data regarding long-term survival benefits will require further follow-up. Conclusions: Progress in peritoneal surface oncology in the Baltic states was confirmed. With a low morbidity and mortality, these clinical programs promise to provide continued benefit for patients with peritoneal metastases - a condition judged to be terminal in the past.

\author{
Schlüsselwörter \\ Hyperthermische intraperitoneale Chemotherapie - HIPEC . \\ Zytoreduktive Chirurgie - ZRC · Pseudomyxoma peritonei . \\ Ovarialkarzinom · Kolorektalkarzinom · Peritonealmetastasen . \\ Peritonektomie
}

\section{Zusammenfassung}

Hintergrund: Weltweit ist ein neues Interesse am fachübergreifenden Management von Peritonealmetastasen mithilfe von neoadjuvanter Chemotherapie, zytoreduktiver Chirurgie (ZRC), hyperthermischer intraperitonealer Chemotherapie (HIPEC) und adjuvanter systemischer Chemotherapie entstanden. Der kombinierte Einsatz dieser Behandlungsmethoden hat die Schaffung von Exzellenzzentren erfordert, um Patienten mit Peritonealmetastasen mit einem hohen $\mathrm{Ma}$ an Erfolg sowie einer geringen Inzidenz an Nebenwirkungen zu behandeln. Methoden: Ein zweitägiger Workshop mit 230 Teilnehmern wurde vom Zentrum für Abdominalchirurgie des Vilnius University Hospital organisiert, um die derzeitige Praxis in den baltischen Staaten zu analysieren. Live-Chirurgie mit Videoübertragung stellte den Beginn der Zusammenarbeit dar. Darauf folgten Präsentationen von fünf Experten aus «High volume"-Zentren für Malignome der Peritonealoberfläche und anschließende Diskussionen. Zusammenfassungen der bisherigen Bestrebungen in Litauen und Estland wurden vorgestellt und zur Veröffentlichung gesammelt. Ergebnisse: Die Live-Chirurgie fungierte als Ausgangspunkt für alle nachfolgenden Präsentationen. Die fünf eingeladenen Referenten bewerteten die Vorgehensweise, die aktuelle Literatur, die Indikationen und Kontraindikationen, die Implementierung sowie die aktuellen europäischen Leitlinien für das Management. Die Ergebnisse der ZRC und HIPEC aus fünf derzeit aktiven Zentren in Litauen und Estland bezogen sich auf bislang 127 behandelte Patienten, von denen die Hälfte die Diagnose eines Ovarialkarzinoms erhalten hatte. Es lagen eine Inzidenz für schwere Komplikationen von $11,8 \%$ und eine Sterblichkeit von 1,6\% vor. Daten zu langfristigen Überlebensvorteilen erfordern ein weiteres Follow-up. Schlussfolgerungen: Fortschritte im Bereich der Onkologie der Peritonealoberfläche in den baltischen Staaten wurden bestätigt. Verbunden mit einer niedrigen Morbidität und Mortalität, versprechen diese klinischen Programme einen weiterhin fortgesetzten Nutzen für Patienten mit Peritonealmetastasen - ein Befund, der in der Vergangenheit mit einem tödlichen Verlauf assoziiert wurde.

\section{KARGER \\ Fax +497614520714

(C) 2014 S. Karger GmbH, Freiburg

$1662-6664 / 14 / 0305-0353 \$ 39.50 / 0$ 


\section{Introduction}

On 15-17 May 2014, Vilnius University Hospital hosted 230 participants and five international experts in peritoneal surface oncology to a workshop entitled 'HIPEC and Complicated Colorectal Surgery'. This report of the conference will focus on the presentations concerning cytoreductive surgery (CRS) and hyperthermic intraperitoneal chemotherapy (HIPEC) for peritoneal metastases. The initial portion of the program featured presentations by the visiting experts from high-volume peritoneal surface malignancy centers in the United States and Europe. Intermittently, a live video was transmitted to the participants from the operating room, and there was a free exchange of questions and answers between the operating theater and the amphitheater. On the second day, the centers in Estonia and Lithuania performing CRS and HIPEC reviewed their initial experience in the management of peritoneal surface malignancy. Latvia provided over a dozen participants to the workshop and provided valuable presentations to the sessions on complicated colorectal surgery but had not, as yet, moved to the treatment of peritoneal metastases. This manuscript is a review of the information made available to the conference participants.

\section{Video Transmission from the Operating Theater to the Amphitheater}

The live surgery added greatly to the overall goals of the CRS and HIPEC workshop for all participants. In real time, it provided a verification of this new concept for the management of a disease process regarded in the past as a terminal condition only to be palliated. The patient was a 67 -year-old woman with a diagnosis of ovarian cancer with persistent disease despite the use of all traditional treatment modalities. Her initial surgery established a diagnosis of ovarian malignancy and removed the uterus, ovaries, and infracolic omentum. Her initial chemotherapy treatments were interrupted by a myocardial infarction. Her current evaluation by computed tomography (CT) after completion of standard ovarian cancer treatments revealed gross disease beneath the right hemidiaphragm, in the right paracolic sulcus, and in the pelvis. Also, according to $\mathrm{CT}$, the visceral peritoneal surfaces of the small bowel mesentery were layered by cancer.

During the surgery, peritonectomy of the right upper quadrant and pelvis were demonstrated. A visceral resection of the rectosigmoid colon was performed with a colorectal anastomosis. As expected from the preoperative CT, the major surgical challenge to a complete cytoreduction was the confluence of disease on the small bowel mesentery. As is frequently observed, the small bowel itself was free of ovarian cancer implants so that small bowel resection was not required. The patient's small bowel mesentery contained copious adipose tissue. Using an angulated electrosurgical tip at moderate-tohigh electrosurgical voltage, the mesenteric peritoneum with the overlying invasive ovarian cancer was resected a few millimeters at a time. Eventually, these mesenteric surfaces were cleared of cancer and a complete cytoreduction was observed.

Following the CRS, the tubes, drains, and temperature probes required for HIPEC were positioned. The HIPEC was completed with cisplatin at $75 \mathrm{mg} / \mathrm{m}^{2}$ in 31 of chemotherapy solution at $42^{\circ} \mathrm{C}$ within the whole abdomen for $1 \mathrm{~h}$. The patient tolerated the surgical procedure and the HIPEC well and was extubated approximately $5 \mathrm{~h}$ after the completion of the procedure.

Information gathered in follow-up at the time of the writing of the manuscript revealed that the patient had no major postoperative complications and a hospital stay of 15 days and that a complete recovery is expected. Certainly, from the perspective of the participants, the added effort in conference planning for a live intraoperative video transmitted to the auditorium was greatly appreciated. It provided reality to the conference as a whole and was often referred to during the remainder of the meeting.

\section{A New Goal for the Treatment of Peritoneal Metastases Is Cure}

The first international speaker was Paul H. Sugarbaker from Washington, DC, USA. The title of his presentation was 'Peritoneal Metastases Can Be Cured'. His thesis was that peritoneal metastases from colorectal cancer can be cured similar to the benefits that are expected in patients with colorectal liver metastases. In 2014, gastrointestinal cancer surgeries require proper clearance combined with maximal containment of the malignant process in order to prevent spillage of cancer cells; also a knowledgeable use of CRS and HIPEC in selected patients is necessary. This new standard of care requires a new chemotherapy methodology in selected patients. The chemotherapy is used only with minimal (microscopic) residual disease. The chemotherapy administration is intraperitoneal or combined intraperitoneal and intravenous. Most importantly, the timing of this new chemotherapy strategy is perioperative. It is neither adjuvant chemotherapy nor neoadjuvant chemotherapy but the simultaneous administration of cancer chemotherapy with CRS.

The paradigm for success in the management of peritoneal metastases is appendiceal epithelial neoplasms. The best results of treatment are complete CRS using peritonectomy and visceral resections combined with perioperative chemotherapy. When this new strategy is compared to traditional treatments with resection and systemic chemotherapy still used at major institutions around the world, their results are inferior to this new strategy [1]. The explanation for these superior results with this new timing of cancer chemotherapy rests in the tumor cell entrapment hypothesis. This hypothesis suggests that cancer cells, at the time of a surgical procedure, are released from severed lymphatic channels, from trauma to the malignancy, or from ve- 
nous blood that remains behind after the surgery. Cancer cells from these sources will implant in the raw surfaces created by the surgery as a local recurrence or at a distance as peritoneal metastases. HIPEC will prevent tumor cell entrapment.

With a low-grade appendiceal malignancy with peritoneal metastases, $75 \%$ of patients may be alive and well 20 years after the treatment. With high-grade peritoneal metastases from appendiceal malignancy, survival at 20 years is approximately $25 \%$ [2]. These data that have changed the history of surgery for appendiceal malignancy are heavily dependent upon the completeness of cytoreduction. Patients with incomplete removal of the tumor have a markedly inferior survival as compared to those with complete removal. Sugarbaker's conclusion was that debulking of appendiceal epithelial neoplasms with peritoneal dissemination is no longer acceptable. The new standard of care is CRS and HIPEC.

Peritoneal metastases from colorectal cancer can also be cured by CRS and HIPEC. Recent data from the MedStar Washington Hospital Center shows a median survival of 5 years in patients who have a complete cytoreduction. Patients with an incomplete cytoreduction but a maximal surgical effort combined with HIPEC have a median survival of 27 months. This 27-month survival with small-to-moderate volume residual disease strongly suggests that the HIPEC is capable of downregulating the aggressiveness of the malignant process on peritoneal surfaces.

Another important prognostic indicator for colon cancer with peritoneal metastases is the peritoneal cancer index. This index remains an important prognosticator even if the cytoreduction has been complete. The other prognostic indicators that are important are the lymph node status of the primary malignancy and the use of adjuvant chemotherapy [3].

A criticism of CRS and HIPEC for colorectal malignancy has been its morbidity and mortality. Sugarbaker showed data on 147 consecutive patients where the mortality was $0.6 \%$ and the rate of grade IV adverse events was $12 \%$. His conclusion was that CRS and HIPEC in selected patients is the new standard of care for peritoneal metastases. Further randomized trials are unnecessary. Acceptance of the resection of liver metastases from colorectal cancer is a reality [4]. Sugarbaker concluded that there is no evidence from the oncology literature that systemic chemotherapy alone is an adequate treatment for the subset of colorectal cancer patients with disease limited to the peritoneal surfaces. Until more data becomes available, the management strategies supported by the literature is CRS and HIPEC. The treatment offers the results to which all other treatment should be compared.

\section{Building a Successful Peritoneal Surface Malignancy Program}

Vadim Gushchin from the Mercy Cancer Center in Baltimore, USA, was asked to present on 'Building a Successful
Peritoneal Surface Malignancy Program'. Drawing on his own experience as well as on prior publications, an approach designed to provide long-term success in the management of this 'final frontier' was proposed [5]. Gushchin suggested that not only the patients but also the institution that establishes a program will benefit from their efforts in peritoneal surface oncology. The personnel working with these patients will gain firsthand new knowledge concerning the biology of gastrointestinal and gynecologic malignancy. The surgical service will of necessity acquire new technical expertise that will benefit all patients. The surgical support services will be forced to expand in order to accommodate these high-acuity patients with increasing efficiency. Finally, data and concepts accumulated in the management of patients with peritoneal metastases provide fresh clinical and basic science research activity. In the short term, the establishment of a successful peritoneal surface malignancy program requires time, effort, and money for the institution; in the long term, however, there will be large benefits both to patients and to the institution.

Gushchin emphasized the need for a surgeon as the team leader. His/her role in the operating theater to successfully complete the cytoreduction should not be underestimated. There is a requirement of the cytoreductive surgeon to move efficiently with resections and reconstructions in all parts of the abdomen and pelvis. This is a level of surgical expertise above that required of the general or oncologic surgeon. However, this surgeon leader is a partner in a team that involves anesthesia, nursing, and multiple levels of support personnel. In order to achieve the necessary success, knowledgeable patient selection, critical evaluation of results, and avoidance of serious complications (especially early in patient accrual) are required.

Several strategies to establish a new peritoneal surface malignancy center were suggested. The core group of physicians, administrators, and other professionals should identify the immediate and long-term goals of the program and move towards these goals systematically. Cooperation with an established center for peritoneal malignancy is highly recommended. Mentorship in all aspects of program development (not only in technical aspects of the surgery) allows reducing the number of cases to achieve oncological proficiency in CRS/HIPEC [6]. Regional cooperation of emerging and established CRS/HIPEC groups is another helpful strategy and was highly encouraged.

\section{CRS and HIPEC Perspectives in the Treatment of Advanced Colorectal Cancer}

Tom Cecil from the well-known Peritoneal Surface Malignancy Program in Basingstoke, UK, presented the data supporting the new United Kingdom guidelines from the Commissioning Board regarding the current policy for the management of peritoneal carcinomatosis from colorectal cancer. 
These guidelines were adopted in April of 2013 [7]. Data to support this revolution in the management of colorectal cancer comes from animal models [8], dozens of single-institution phase II trials [9], the Verwaal/Zoetmulder randomized controlled trial [10], and international as well as French multiinstitutional data $[11,12]$. Data which establishes that properly selected patients who receive CRS/HIPEC plus the best systemic chemotherapy survive better than patients who receive systemic chemotherapy alone can no longer be ignored by the panels formulating guidelines for standard of care [13].

From the extensive Basingstoke experience, Cecil presented his recommendations for best outcomes for the management of colorectal cancer peritoneal metastases. First, an established program with a large experience will, by its continued ascent of the learning curve, reduce the mortality and decrease the incidence of adverse events. Then, one must identify by $\mathrm{CT}$ and or preoperative laparoscopy those patients with a peritoneal cancer index of less than 20. Even though the cytoreduction is complete for colorectal cancer, the peritoneal cancer index has profound prognostic implications. Third, whenever possible, treat the peritoneal metastases that occur synchronously with the primary colon or rectal cancer definitively by a single primary cancer resection, surgical cytoreduction, and HIPEC. This avoids the tumor cell entrapment phenomenon, an especially devastating occurrence in patients with rectal cancer with peritoneal metastases. Fourth, even though CRS and HIPEC seem adequate, maximally utilize systemic chemotherapy.

The purpose of careful patient selection and the goal of meticulous cytoreduction is a complete visible resection of disease from the whole abdomen and pelvis. Cecil suggested future perspectives to be improved patient selection through improved radiologic imaging, improved patient selection by more frequent laparoscopic procedures, improved perioperative chemotherapy regimens designed to increase the proportion of patients whose complete surgical response by cytoreduction is preserved by HIPEC, and identification of patients at high risk for progression of peritoneal metastases for proactive management strategies.

\section{Peritoneal Metastases from Epithelial Ovarian Cancer}

Marcello Deraco from the Istituto Tumori, Milan, Italy, reviewed his own experience and the world literature concerning the current role of CRS and HIPEC in epithelial ovarian cancer. Deraco introduced this subject by commenting on the many unknowns for this disease and the relatively few established treatments. Much clinical research has established that a dominant prognostic factor for epithelial ovarian cancer is the extent of residual disease at the completion of the CRS. He stated emphatically that the goal of surgery for ovarian cancer must be complete visible clearing of the disease from the abdomen and pelvis. This is the goal of resection at the time of primary cancer treatment, at the time of interval cytoreduction after neoadjuvant chemotherapy, and at the time of surgery for disease progression in selected patients. Of course, only a surgery that the patient can survive and a surgical technology with which the operator has confirmed experience should be implemented.

Data from Chi et al. [14] at the Memorial Sloan-Kettering Cancer Center was cited. They tested the concept of complete cytoreduction from the experience at their institution. This group supplemented the technical expertise of the gynecologic oncologist by using thoracic surgical expertise to strip the peritoneum from the undersurface of the hemidiaphragms or partially resect these structures. They used the hepatobiliary surgical expertise to clear the perihepatic regions and also used surgical oncology expertise for bowel resections, splenectomy, and occasionally partial gastrectomy. The expertise of the Memorial Sloan-Kettering Cancer Center surgical intensive care unit was utilized to keep postoperative care at its highest level.

The survival of patients from 1996 to 1999 treated with traditional debulking surgery was compared to the survival after the year 2000 after implementing complete cytoreduction using all of the expertise of the surgical oncologic subspecialties. The systemic chemotherapy over the decade of this data gathering did not change. Median survival increased from $35 \%$ in the debulked group to $47 \%$ in the group with attempted complete cytoreduction $(\mathrm{p}=0.03)$ [14].

Long-term combined intravenous and intraperitoneal chemotherapy has been shown to benefit ovarian cancer patients [15]. Deraco suggested that the next logical step would include cancer chemotherapy as a part of the CRS. Deraco and his Italian collaborators combined complete cytoreduction, HIPEC with cisplatin and doxorubicin, with the best systemic chemotherapy. In this multi-institutional phase II study with HIPEC being added up front to cytoreduction, there was a median survival of 60 months [16]. Also, a recent multi-institutional phase II study reported by Bakrin et al. [17] shows an excellent long-term survival when HIPEC is added to complete cytoreduction.

Many of the issues regarding sequencing of treatments for ovarian cancer remain unanswered. Should the chemotherapy be delivered preoperatively as neoadjuvant chemotherapy or only after the CRS? What has been established as an optimal management is complete surgical resection of all visible disease and systemic or bidirectional chemotherapy with cisplatin and paclitaxel. With an abundance of publications suggesting superior results with perioperative chemotherapy using HIPEC, this treatment can be recommended by experienced groups in selected patients. Until more data becomes available from prospective and randomized trials of HIPEC versus no HIPEC following complete cytoreduction, this treatment strategy is the preferred strategy at institutions that can safely and effectively perform complete CRS, HIPEC, and the indicated systemic chemotherapy. 
Table 1. Survey of management of peritoneal metastases, cytoreductive surgery (CRS), and hyperthermic intraperitoneal chemotherapy (HIPEC) in Estonia and Lithuania

\begin{tabular}{|c|c|c|c|c|c|c|c|}
\hline & $\begin{array}{l}\text { Tallinn, } \\
\text { Estonia }\end{array}$ & $\begin{array}{l}\text { North } \\
\text { Estonia } \\
\text { Medical } \\
\text { Center }\end{array}$ & $\begin{array}{l}\text { Tartu } \\
\text { University } \\
\text { Hospital, } \\
\text { Estonia }\end{array}$ & $\begin{array}{l}\text { Klaipeda, } \\
\text { Lithuania }\end{array}$ & $\begin{array}{l}\text { Abdominal } \\
\text { Surgery, } \\
\text { Vilnius, } \\
\text { Lithuania }\end{array}$ & $\begin{array}{l}\text { Oncologic } \\
\text { Institute, } \\
\text { Vilnius, } \\
\text { Lithuania }\end{array}$ & Total \\
\hline Reporting surgeon & Arak & Suuroja & $\begin{array}{l}\text { Soplepmann, } \\
\text { Magi, Tammik }\end{array}$ & Slepavicius & Strupas & Rudinskaite & \\
\hline $\begin{array}{l}\text { Duration of active } \\
\text { CRS/HIPEC activity, years }\end{array}$ & 5 & 3 & 2.5 & 2 & 3 & 1 & \\
\hline $\begin{array}{l}\text { Total patients } \\
\text { Diagnosis }\end{array}$ & 37 & 23 & 24 & 14 & 25 & 4 & 127 \\
\hline Ovarian & 21 & 1 & 14 & 8 & 18 & 2 & 64 \\
\hline Colorectal & 5 & 13 & 6 & 3 & 2 & 2 & 31 \\
\hline Appendix and PMP & 2 & 2 & 2 & 3 & 5 & & 14 \\
\hline Gastric & 6 & 7 & 2 & & & & 15 \\
\hline Other & 3 & & & & & & 3 \\
\hline Class IV complications ${ }^{\mathrm{a}}$ & $2(5 \%)$ & $5(22 \%)$ & $3(12.5 \%)$ & 0 & $4(16 \%)$ & $1(25 \%)$ & $15(11.8 \%)$ \\
\hline Deaths & 0 & $2(8.7 \%)$ & 0 & 0 & 0 & 0 & $2(1.6 \%)$ \\
\hline
\end{tabular}

${ }^{\text {a}}$ Return to OR or SICU for complications.

$\mathrm{PMP}=$ Pseudomyxoma peritonei; $\mathrm{OR}=$ operating room; $\mathrm{SICU}=$ surgical intensive care unit.

\section{Indications and Contraindications for the Management of Colorectal Peritoneal Metastases by CRS and HIPEC}

Beate Rau from the Charite Hospital, Berlin, Germany, reminded the group that there are multiple clinical manifestations of 'peritoneal metastases'. It is not surprising that therapeutic options to be considered are palliation by best supportive care, single or multiple paracentesis, long-term systemic or intraperitoneal chemotherapy, catumaxomab, or CRS/HIPEC.

Rau conceptualized the contraindications for management of colorectal metastases by CRS/HIPEC. Naturally, a preoperative assessment strongly suggesting that a complete cytoreduction is not possible is a contraindication. Also, unresectable systemic disease or unresectable hepatic metastases are a contraindication. Patients with other conditions such as increased age, severe prior treatments, or other comorbid conditions that indicate a poor 'functional recovery potential' should be excluded.

The German healthcare system includes CRS/HIPEC as within guidelines [18]. The German system for benchmarking the management of colorectal cancer patients with peritoneal metastases who receive CRS/HIPEC is part of this process. Certification in Germany requires a high standard of care for reimbursement for services from the national healthcare system. Requirements for certification indicate that the multidisciplinary team must be integrated into the care of patients with peritoneal metastases. These patients cannot be treated in isolation. Skilled performance of CRS must occur to avoid a 'culture of failure'. Participation in German national and European clinical trials is required in approximately $10 \%$ of the patients. Data management with registry of selected items for all patients is mandatory. The goal of the benchmarking project is to accumulate a German database that allows for a standard of care to which all institutions involved in CRS and HIPEC can self-scrutinize their results.

\section{Data from the Baltic States Regarding Clinical Experience to Date with CRS and HIPEC}

On the second day of the workshop, peritoneal surface malignancy centers from Estonia and Lithuania presented their results to date with CRS and HIPEC. Since follow-up is relatively short and the number of patients limited, data focused on the number of patients, diagnosis of patients, morbidity, and mortality. Survival statistics will be reviewed at a later date. Andrus Arak reported data from the East Tallinn Central Hospital in Tallinn, Estonia. Arak commented that his institution is one of three centers currently performing CRS/ HIPEC in Estonia. To date, $37 \mathrm{CRS} / \mathrm{HIPEC}$ procedures have been completed at his institution. 21 patients carried a diagnosis of ovarian cancer, and the other patients had primarily gastric or colon cancer. Diaphragm resection was required in 7 patients, and these patients received hyperthermic thoracoabdominal chemotherapy (HITAC) [19]. There were no open and closed procedures. $38 \%$ of the patients had a CC- 1 and $62 \%$ of the patients a CC- 0 cytoreduction. For ovarian cancer, the single agent cisplatin was used at $90 \mathrm{mg} / \mathrm{m}^{2}$, and for gastric and colorectal cancer, mitomycin $\mathrm{C}$ was administered at 35 $\mathrm{mg} / \mathrm{m}^{2}$. There were two class IV gastrointestinal adverse events (table 1 ). 
Although not presented at the conference, data was obtained from Suuroja at North Estonia Medical Center and Soplepmann, Magi, and Tammik at Tartu University Hospital, Estonia. Their data is included in table 1.

Arminas Slepavicius reported the results of CRS/HIPEC from Klaipeda University Hospital in Klaipeda, Lithuania. A total of 14 patients have been treated so far: 8 with ovarian cancer, 3 with colorectal cancer, and 3 with appendiceal pseudomyxoma peritonei. Slepavicius emphasized that close collaboration with medical oncology was a standard of care. The medical oncologist determined the doses of HIPEC while monitoring the procedure in the operating room. The project emphasizes a multiple disciplinary team effort and a high quality of care (table 1 ).

Jonas Jurgaitis from Vilnius University, Vilnius, Lithuania, reported on 25 patients. There were 18 ovarian cancer patients, 2 colon cancer patients, and 5 pseudomyxoma peritonei patients. They reported 3 anastomotic leaks in this group of 25 patients. There were no deaths (table 1 ).

Giedre Rudinskaite from the Institute of Oncology of Vilnius University, Vilnius, Lithuania, reported on 4 patients treated within the last year. The open technique for HIPEC was used. There was a single anastomotic insufficiency that did not result in mortality (table 1).

\section{Conclusions within a Historical Perspective}

This first regional workshop in peritoneal surface oncology hosted by the Vilnius University attests to the three decades of efforts and continuing progress in the successful management of peritoneal metastases. The initial success came about through the combination of two innovations in patient management. Early in this experience it became clear that a first requirement for benefit was the complete or near complete resection of both parietal peritoneal and visceral peritoneal cancer implants. The surgical concept of complete cytoreduction would evolve as peritonectomy procedures were combined with visceral resections and were incorporated into the surgical oncologists' technological armamentarium [20]. The second requirement for benefit was a pharmacologic rationale for perioperative intraperitoneal chemotherapy [21-23]. This new cancer chemotherapy is neither neoadjuvant therapy nor adjuvant chemotherapy but perioperative chemotherapy to be used as a planned part of the cancer resection. It is cancer chemotherapy treatments integrated into the surgical resection of a malignancy within the abdomen and/or pelvis.

Increasing success and expansion of this combined treatment has occurred over three decades. The complete cytore- ductive surgical procedure remains as a continuing surgical oncologic challenge. Even in the most experienced groups, incomplete cytoreductions occur, adverse events arise, and mortality continues. Educational efforts in peritoneal surface oncology were the strong motivation for the Vilnius workshop, in order to avoid a long and steep 'learning curve'. The workshop at Vilnius University was a timely event designed to convey concepts in patient selection, techniques of cytoreduction, and results expected using combined treatments of CRS/ HIPEC.

The parietal and visceral peritonectomy procedures are an extension of a 100 years of surgical expertise. These new surgical technologies have been rapidly integrated into surgical practice and continue to be improved. However, the HIPEC is a relatively new cancer treatment. Its limited use began less than two decades ago. Flessner and Dedrick established the pharmacologic advantage for some drugs instilled directly into the peritoneal space to treat cancer cells or minute cancer nodules [23]. From a pharmacologic perspective and in actuality, only extremely small cancer deposits can be affected by intraperitoneal drugs entering into the cancerous tissue or the surrounding peritoneum by simple diffusion. This fact establishes the requirement for complete cytoreduction to microscopic residual disease for optimal results.

However, even today the single agent intraperitoneal mitomycin $\mathrm{C}$, a drug with a systemic response rate of approximately $15 \%$, is the drug of choice for hyperthermic peritoneal lavage. In Europe, intraperitoneal oxaliplatin is widely used at pharmacologic doses over a short duration with short-term (30 min) hyperthermia. To date, no significant difference with HIPEC mitomycin C versus HIPEC oxaliplatin has been reported. It is possible that neither of these regimens optimally provides the chemotherapeutic effect required to preserve the surgical complete response achieved by cytoreduction.

New drugs and drug combinations for HIPEC are being explored. Efforts to use pharmacologic information in order to combine intravenous and intraperitoneal cancer chemotherapy agents are being published [24]. The goal must be for HIPEC to more reliably preserve the surgical complete response obtained by the complete CRS. Perioperative combined hyperthermic and systemic chemotherapy and perhaps long-term bidirectional chemotherapy may compliment the benefits of CRS and HIPEC.

\section{Disclosure Statement}

The authors have no conflicts of interest to declare. 


\section{References}

1 Sugarbaker PH: New standard of care for appendiceal epithelial malignancies and pseudomyxoma peritonei syndrome. Lancet Oncol 2006;7:69-76.

2 Sugarbaker PH: Pseudomyxoma peritonei and peritoneal metastases from appendiceal malignancy; in Sugarbaker PH (ed): Cytoreductive Surgery \& Perioperative Chemotherapy for Peritoneal Surface Malignancy. Textbook and Video Atlas. Woodbury, CT, Cine-Med Publishing, 2012, pp 57-78.

3 Elias D, Gilly F, Boutitie F, Quenet F, Bereder JM, Mansvelt B, Lorimier G, Dube P, Glehen O: Peritoneal colorectal carcinomatosis treated with surgery and perioperative intraperitoneal chemotherapy: retrospective analysis of 523 patients from a multicentric French study. J Clin Oncol 2009;28:63-68.

4 Glasziou P, Chalmers I, Rawlins M, McCulloch P: When are randomised trials unnecessary? Picking signal from noise. BMJ 2007;334:349-351.

5 Gonzalez-Bayon L, Sugarbaker PH, GonzalezMoreno S, de Lima Vazquez V, Alves S, Moran B: Initiation of a program in peritoneal surface malignancy. Surg Oncol Clin N Am 2003;12:741-753.

6 Kusamura S, Baratti D, Virzì S, Bonomi S, Iusco DR, Grassi A, Hutanu I, Deraco M: Learning curve for cytoreductive surgery and hyperthermic intraperitoneal chemotherapy in peritoneal surface malignancies: analysis of two centres. J Surg Oncol 2013; 107:312-319.

7 NHS Commissioning Board: Clinical Commissioning Policy for Cytoreductive Surgery with Hyperthermic Intraperitoneal Chemotherapy for Peritoneal Carcinomatosis. NHSCB/A08/P/a April 2013. www.england.nhs.uk/wp-content/uploads/2013/09/ a08-p-a.pdf.

$\checkmark 8$ Koga S, Hamazoe R, Maeta M, Shimizu N, Kanayama H, Osaki Y: Treatment of implanted peritoneal cancer in rats by continuous hyperthermic peritoneal infusion in combination with an anticancer drug. Cancer Res 1984;44:1840-1842.

9 Yan TD, Black D, Savady R, Sugarbaker PH: Systematic review on the efficacy of cytoreductive surgery combined with perioperative intraperitoneal chemotherapy for peritoneal carcinomatosis from colorectal carcinoma. J Clin Oncol 2006;24:40114019 .
10 Verwaal VJ, van Ruth S, de Bree E, van Sloothen GW, van Tinteren H, Boot H, Zoetmulder FA: Randomized trial of cytoreduction and hyperthermic intraperitoneal chemotherapy versus systemic chemotherapy and palliative surgery in patients with peritoneal carcinomatosis of colorectal cancer. J Clin Oncol 2003;21:3737-3743.

11 Glehen O, Kwiatkowski F, Sugarbaker PH, Elias D, Levine EA, De Simone M, Barone R, Yonemura Y, Cavaliere F, Quenet F, Gutman M, Tentes AA, Lorimier G, Bernard JL, Bereder JM, Porcheron J, Gomez-Portilla A, Shen P, Deraco M, Rat P: Cytoreductive surgery combined with perioperative intraperitoneal chemotherapy for the management of peritoneal carcinomatosis from colorectal cancer: a multi-institutional study. J Clin Oncol 2004;22:3284-3292.

12 Elias D, Gilly F, Glehen O: Carcinoses péritonéales d'origine digestive et primitive. Arnette/Paris, L'association Francaise de Chirurgie, 2008.

13 Mirnezami R, Mehta AM, Chandrakumaran K, Cecil T, Moran BJ, Carr N, Verwaal VJ, Mohamed F, Mirnezami AH: Cytoreductive surgery in combination with hyperthermic intraoperative chemotherapy improves survival in patients with colorectal peritoneal metastases compared with systemic chemotherapy alone. Br J Cancer 2014;DOI: 10.1038/bjc.2014.419.

14 Chi DS, Eisenhauer EL, Zivanovic O, Sonoda Y, Abu-Rustum NR, Levine DA, Guile MW, Bristow RE, Aghajanian C, Barakat RR: Improved progression-free and overall survival in advanced ovarian cancer as a result of a change in surgical paradigm. Gynecol Oncol 2009;114:26-31.

5 Armstrong DK, Bundy B, Wenzel L, Huang HQ, Baergen R, Lele S, Copeland LJ, Walker JL, Burger RA; Gynecologic Oncology Group: Intraperitoneal cisplatin and paclitaxel in ovarian cancer. N Engl J Med 2006;354:34-43.

16 Deraco M, Kusamura S, Virzì S, Puccio F, Macrì A, Famulari C, Solazzo M, Bonomi S, Iusco DR, Baratti D: Cytoreductive surgery and hyperthermic intraperitoneal chemotherapy as upfront therapy for advanced epithelial ovarian cancer: multi-institutional phase-II trial. Gynecol Oncol 2011;122:215-220.
7 Bakrin N, Cotte E, Golfier F, Gilly FN, Freyer G, Helm W, Glehen O, Bereder JM: Cytoreductive surgery and hyperthermic intraperitoneal chemotherapy (HIPEC) for persistent and recurrent advanced ovarian carcinoma: a multicenter, prospective study of 246 patients. Ann Surg Oncol 2012;19: 4052-4058.

18 Hypertherme intraperitoneale Chemotherapie (HIPEC) in Kombination mit Peritonektomie und ggf. mit Multiviszeralresektion, ZE2007-4. Institut für das Entgeltsystem im Krankenhaus gGmbH, 2013.

19 Sugarbaker PH, Chang D, Stuart OA: Hyperthermic intraoperative thoraco-abdominal chemotherapy. Gastroenterol Res Pract 2012;2012:623417.

20 Sugarbaker PH: An overview of peritonectomy, visceral resections, and perioperative chemotherapy for peritoneal surface malignancy; in Sugarbaker PH (ed): Cytoreductive Surgery \& Perioperative Chemotherapy for Peritoneal Surface Malignancy. Textbook and Video Atlas. Woodbury, CT, Cine-Med Publishing, 2012, pp 1-30.

21 Spratt JS, Adcock RA, Muskovin M, Sherrill W, McKeown J: Clinical delivery system for intraperitoneal hyperthermic chemotherapy. Cancer Res 1980;40:256-260.

22 Koga S, Hamazoe R, Maeta M, Shimizu N, Murakami A, Wakatsuki T: Prophylactic therapy for peritoneal recurrence of gastric cancer by continuous hyperthermic peritoneal perfusion with mitomycin C. Cancer 1988;61:232-237.

23 Flessner MF, Dedrick RL, Schultz JS: Exchange of macromolecules between peritoneal cavity and plasma. Am J Physiol 1985;248:H15-25.

24 Van der Speeten K, Stuart OA, Sugarbaker PH: Pharmacology of perioperative cancer chemotherapy; in Sugarbaker PH (ed): Cytoreductive Surgery \& Perioperative Chemotherapy for Peritoneal Surface Malignancy. Textbook and Video Atlas. Woodbury, CT, Cine-Med Publishing, 2012, pp 159-182. 